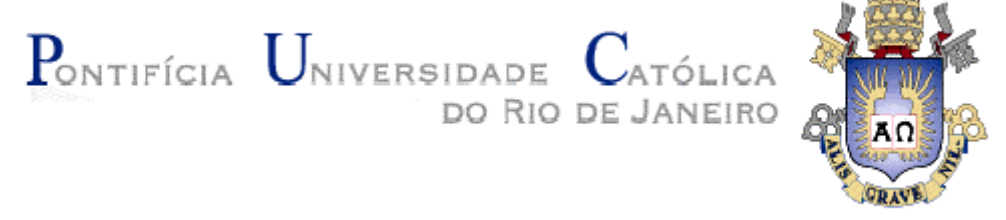

Diana Sayão Vieira

Educação de Jovens e Adultos e Pluralidade Cultural: a realidade de um Colégio Supletivo de Ensino Médio

Dissertação de Mestrado

Dissertação apresentada como requisito parcial para obtenção do grau de Mestre pelo Programa de Pós-Graduação em Educação do Departamento de Educação da PUC-Rio.

Orientador: Profa ${ }^{a}$ Vera Maria Ferrão Candau 
Diana Sayão Vieira

\title{
Educação de Jovens e Adultos e Pluralidade Cultural: a realidade de um Colégio Supletivo de Ensino Médio
}

Dissertação apresentada como requisito parcial para obtenção do grau de Mestre pelo Programa de Pós-Graduação em Educação do Departamento de Educação do Centro de Teologia e Ciências Humanas da PUC-Rio. Aprovada pela Comissão Examinadora abaixo assinada.

\author{
Prof ${ }^{a}$. Vera Maria Ferrão Candau \\ Orientadora \\ Departamento de Educação - PUC-Rio
}

Prof. Jose Carmello Braz de Carvalho

Departamento de Educação - PUC-Rio

Prof Ivanilde Apoluceno de Oliveira UEPA

Profa $^{\text {a }}$ Denise Berruezo Portinari Coordenador Setorial do Centro de Teologia e Ciências Humanas

Rio de Janeiro, 03 de maio de 2011. 
Todos os direitos reservados. É proibida a reprodução total ou parcial do trabalho sem autorização da universidade, da autora e do orientador.

\section{Diana Sayão Vieira}

Graduou-se como Bacharel em Biologia Marinha pela UFRJ (Universidade Federal do Rio de Janeiro) em 2005 e Licenciatura em Ciências Biológicas na mesma universidade em 2007. Cursou pós-graduação em Gestão Ambiental também pela UFRJ em 2006. Foi professora substituta do Colégio de Aplicação da UFRJ. Trabalhou como tutora no Projeto Cientistas do Amanhã em parceria com Secretaria Municipal de Educação do Rio de Janeiro. Atualmente é professora de Biologia do Estado do Rio de Janeiro da EJA (Educação de Jovens e Adultos) no ensino médio e professora de ciências da SME no ensino fundamental II. Participa do grupo de estudos GECEC (Grupo de Estudos sobre Cotidiano e Cultura/s) da PUC-Rio sob coordenação da professora Vera M. F. Candau na linha de pesquisa sobre Cotidiano, Educação e Culturas(s).

Ficha Catalográfica

Vieira, Diana Sayão

Educação de jovens e adultos e pluralidade cultural: a realidade de um colégio supletivo de ensino médio / Diana Sayão Vieira ; orientador: Vera Maria Ferrão Candau. - 2011.

147 f. : il. ; $30 \mathrm{~cm}$

Dissertação (mestrado)-Pontifícia Universidade Católica do Rio de Janeiro, Departamento de Educação, 2011.

Inclui bibliografia

1. Educação - Teses. 2. Educação de jovens e adultos. 3. Educação intercultural. 4. Pluralidade cultural. 5. Ensino médio. I. Candau, Vera Maria Ferrão. II. Pontifícia Universidade Católica do Rio de Janeiro. Departamento de Educação. III. Título. 
A todos os meus alunos e alunas da Educação de Jovens e Adultos, pelos ensinamentos e vivências, que alcancem seus objetivos e seus sonhos e nunca desistam de serem mais. 


\section{Agradecimentos}

À Professora Vera Candau, por todos os ensinamentos, sugestões e orientações. Mas principalmente, pela paciência, atenção e compreensão. Obrigado pelo apoio, sempre.

À Professora Ivanilde Apoluceno, pelas conversas sobre a pesquisa que me levaram a refletir bastante no início do estudo. Obrigado pelas sugestões fundamentais para a elaboração do trabalho.

Aos meus pais, Dalton e Mithê, que tudo me ensinaram e que estiveram ao meu lado me aconselhando e incentivando em todos os momentos.

Ao meu marido Ricardo, por toda a ajuda, compreensão, amor e paciência. Você é a razão de todo meu empenho.

Aos meus sobrinhos, Rodrigo e Ana Carolina, por sempre me darem suporte emocional para continuar persistindo utilizando apenas seus sorrisos.

Aos/Às amigos(as) do GECEC (Grupo de Estudos sobre Cotidiano Escolar e Cultura/s) do Departamento de Educação da PUC-Rio, com os(as) quais aprendi muito e continuo aprendendo. Obrigado por estarem comigo nessa jornada.

À todos(as) da turma de Mestrado em Educação da Puc-Rio 2009: Marta, Rodrigo, Fátima, Raquel, Rita, Tatiane, Carla, Cátia, Patrícia, Pâmela, Carol, Marisa, Márcia, Rejane, Cecília, Andréia e Adriana, pela ajuda e momentos que passamos juntos durante o curso.

Ao Professor Carlos Francisco Baptista, por me ensinar tudo que sei sobre a Educação de Jovens e Adultos na prática e por acreditar no meu potencial como educadora.

À amiga Anna Carolina Ayres, por me apresentar ao curso de Mestrado em Educação da PUC-Rio e me incentivar a cada passo trilhado até agora.

Aos/Às professores(as) que participaram da Banca examinadora.

À todos(as) os(as) professores(as) e funcionários(as) do Departamento de Educação da PUC-Rio pela disponibilidade e ajuda durante todo o curso. 


\section{Resumo}

Vieira, Diana Sayão; Candau, Vera Maria Ferrão. Educação de Jovens e Adultos e Pluralidade Cultural: a realidade de um Colégio Supletivo de Ensino Médio. Rio de Janeiro, 2011. 147 p. Dissertação de Mestrado Departamento de Educação, Pontifícia Universidade Católica do Rio de Janeiro.

O presente estudo aborda o tema da Educação de Jovens e Adultos (EJA) no ensino médio supletivo noturno. Focaliza uma escola que desenvolve essa modalidade de ensino, procurando compreendê-la na perspectiva do multiculturalismo crítico, sob a ótica da interculturalidade. Com essa abordagem, foi realizada uma pesquisa qualitativa, mais precisamente um estudo de caso, em um Colégio Estadual do Estado do Rio de Janeiro, denominado Colégio Arpoador. Foram selecionadas como estratégias metodológicas, além da revisão de bibliografia, três técnicas para a coleta de dados: a observação, a análise documental e a entrevista semiestruturada. Os objetivos principais da pesquisa foram: analisar se os(as) professores(as) do Colégio Arpoador reconhecem e trabalham com a realidade heterogênea dos(as) alunos(as), levando em consideração as práticas pedagógicas, o currículo e a construção da(s) identidades dos(as) alunos(as), além de buscar identificar as possíveis contribuições de uma educação intercultural para essa modalidade. Os resultados obtidos através dos depoimentos dos(as) professores(as) indicam que eles reconhecem a grande diversidade cultural dos(as) alunos(as). No entanto, essa realidade não parece ser referência para pensar suas práticas pedagógicas e a seleção do currículo. A educação intercultural não parece ser uma prática conhecida pelos(as) professores(as), mas foi possível perceber um esforço dos(as) mesmos(as) em compreender do que ela trata e como poderia ser promovida no cotidiano escolar. A partir dos resultados, a pesquisa procurou apontar dificuldades encontradas na EJA de ensino médio e sugerir caminhos de renovação, partindo do princípio que a educação intercultural é capaz de trazer múltiplos benefícios para esta realidade.

\section{Palavras-chave:}

Educação de Jovens e Adultos; Educação Intercultural, Pluralidade Cultural; Ensino Médio. 


\section{Abstract}

Vieira, Diana Sayão; Candau, Vera Maria Ferrão. (Advisor). Youth and Adults Education and Cultural Plurality: the reality of a Supplementary High School. Rio de Janeiro, 2011. 147 p. MSc. Dissertation - Departamento de Educação, Pontifícia Universidade Católica do Rio de Janeiro.

This work is a study about the Adults and Youth Education (Educação de Jovens e Adultos -EJA) in an evening high school equivalency program. We have chosen one school that is part of this kind of program and we have tried to understand its functioning under a critic multiculturalism perspective in an interculturallity vision. Starting with this premise, a qualitative research was carried out, in fact a case study, in a public school of the state of Rio de Janeiro, named Colégio Arpoador. The methodological strategies included, besides the bibliography review, three data collection techniques: observation, documental analyses and semi-structured interview. The main objectives were to analyze if Colégio Arpoador's teachers recognize and work with the heterogeneous reality of its students, considering their pedagogical practices, the curriculum and the identity construction, besides identifying the contributions of an intercultural education for this kind of equivalency program. The results obtained from the teacher testimonies indicate that they recognize the existence of a great cultural diversity among students, although this reality seems not to constitute a reference to their pedagogical practices and the curriculum subject selection. It seems that teachers don't experience the intercultural education as a practice, but there is an effort to understand how it works and how it can be stimulated in daily school. From the results, the research tried to show the difficulties found in high school EJA, and also tried to suggest ways to renovate the pedagogical practices, starting from the principle that intercultural education is a very productive way of giving multiples benefits for that reality.

\section{Key-words:}

Youth and Adults Education; Intercultural Education; Cultural Plurality; High School. 


\section{Sumário}

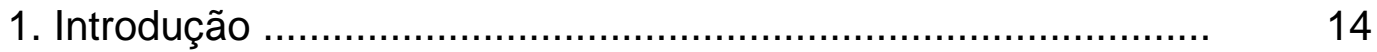

1.1.Justificativa ...................................................................... 14

1.2. Relevância ...................................................................... 16

1.3. Questões, objetivos e campo de pesquisa ........................... $\quad 19$

1.3.1. Questões norteadoras da pesquisa ................................... 20

1.3.2. Objetivos propostos pela pesquisa .................................... 21

1.3.3. A escolha do campo de pesquisa ...................................... 21

1.4. Procedimentos metodológicos da pesquisa .......................... 22

1.5. Estrutura da dissertação ................................................... 26

2. Educação de Jovens e Adultos (EJA) …………..................... 28

2.1. A História da Educação de Jovens e Adultos no Brasil .......... 28

2.2. A Educação de Jovens e Adultos no Estado do Rio de Janeiro: Contexto atual ............................................................... 45

3. Pluralidade cultural, multiculturalismo e Educação de Jovens e Adultos ............................................................................ 50

3.1. Cultura e diversidade cultural no mundo atual ..................... $\quad 50$

3.2.Multiculturalismo: origens e propostas .................................. $\quad 55$

3.2.1. A Origem do Multiculturalismo ........................................ $\quad 55$

3.2.2. Diferentes abordagens do multiculturalismo e suas

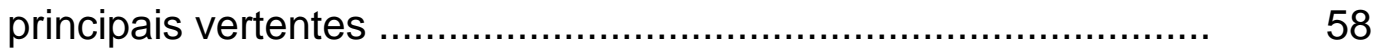

3.3. Escola, diversidade cultural e EJA ....................................... 62

3.3.1. A Cultura na Escola: como tratar a diversidade cultural na

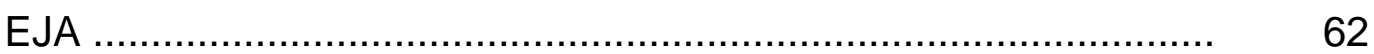

3.3.2. Multiculturalismo na escola: Práticas interculturais na EJA 68

4. Colégio Arpoador: Espaços, Projeto Político Pedagógico e

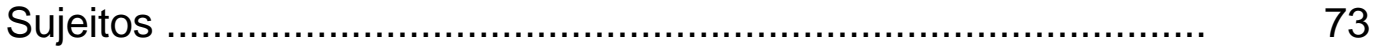

4.1. Caracterizando o Colégio Arpoador ................................... 73 
4.2. A infraestrutura do colégio ..................................................

4.2.1. As salas de aula .........................................................

4.2.2. O pátio e o refeitório ............................................................. 76

4.2.3. A cozinha e o jantar …………....................................... 78

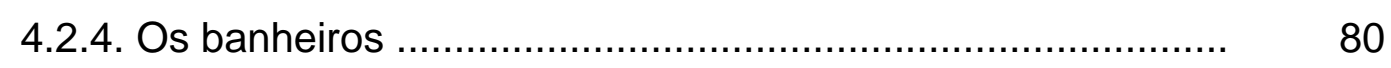

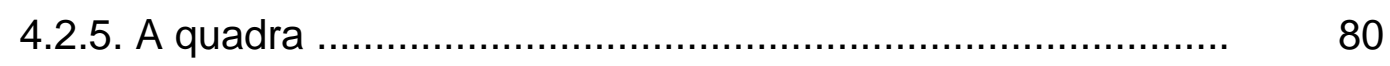

4.2.6. A sala de direção ......................................................... $\quad 80$

4.2.7. O espaço dos(as) professores(as) .................................... $\quad 82$

4.3. Projeto Político Pedagógico do Colégio Arpoador .................. 83

4.4. Perfil dos(as) alunos(as) do Colégio Arpoador ...................... $\quad 87$

4.4.1. Dados de aprovação, reprovação e evasão dos(as)

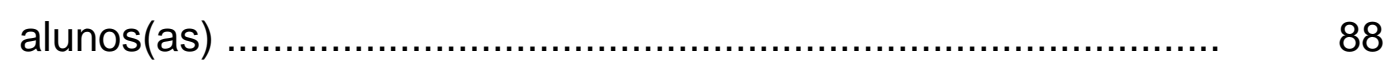

4.4.2. Caracterização dos(as) alunos(as) .................................... 90

4.5. Os(as) professores(as) do Colégio Arpoador ......................... 99

5. Colégio Arpoador e Diversidade Cultural dos(as) alunos(as): como se situam os professores e professoras ............................ 101

5.1. Perfil dos(as) Professores(as) Estudados(as) ...................... 103

5.1.1. Formação Educacional dos(as) Professores(as) do Colégio

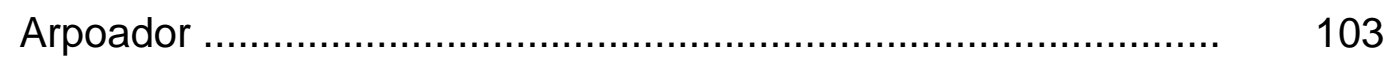

5.1.2. Experiência Profissional dos(as) Professores(as) do Colégio Arpoador …......................................................... 105

5.2. A Experiência dos(as) professores(as) do Colégio Arpoador com a EJA ........................................................................ 107

5.3. Os(as) Alunos(as) de EJA: Origens, Culturas e Características ....................................................................... 110

5.4. O Processo de Ensino-Aprendizagem nas Turmas de EJA ... 118

5.5. Diversidade Cultural e EJA ……....................................... 121

5.6. Outros aspectos relevantes sobre a educação em geral ........ 125

6. Considerações Finais ……………………………............... 127

7. Referências Bibliográficas …………………………….......... 133

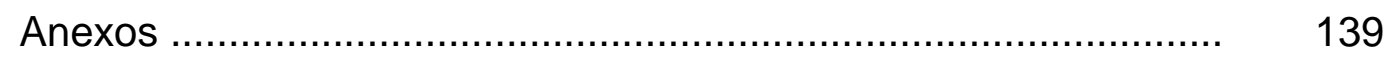




\section{Lista de Figuras}

Figura 1 - Sala de aula do Colégio Arpoador

Figura 2 - Pátio do Colégio Arpoador: visão da entrada do colégio. À direita, o muro que separa o refeitório. Ao fundo, as escadas que sobem para as salas de aula

Figura 3 - Pátio do Colégio Arpoador: visão da escada do colégio. Ao fundo, a porta de entrada do colégio

Figura 4 - Refeitório do Colégio Arpoador

Figura 5 - Refeitório do Colégio Arpoador: visão da escada

77

Figura 6 - Cozinha do Colégio Arpoador: A maioria dos armários ao fundo fica trancada no período noturno

Figura 7 - Cozinha do Colégio Arpoador: A geladeira e o freezer são de uso exclusivo do colégio

Figura 8 - Quadra esportiva do Colégio Arpoador. A foto foi tirada da grade de entrada da quadra, pois esta se encontrava trancada

Figura 9 - Sala da direção do Colégio Arpoador: o pequeno espaço dificulta o trabalho

Figura 10 - Sala da direção do Colégio Arpoador: As caixas com computadores diminuem ainda mais o espaço disponível

Figura 11 - O único espaço dos(as) professores(as): pouco utilizado, serve para armazenar materiais e livros antigos 


\section{Lista de tabelas e quadros}

Tabela 1 - Número de matrículas na educação de jovens e adultos nos cursos presenciais e semipresenciais de Ensino Fundamental e Médio, segundo a dependência administrativa 2006 a 2008. Fonte: MEC/INEP/Sinopse estatística da Educação Básica 2006/2007/2008

Tabela 2 - Alunos(as) aprovados(as), reprovados(as) e evadidos(as) em cada ano e no total no $1^{\circ}$ semestre de 2010 .......

Tabela 3 - Alunos(as) aprovados(as), reprovados(as) e evadidos(as) por ano e no total no $2^{\circ}$ semestre de 2010

Tabela 4 - Quantidade de professores(as) por disciplina do Colégio Arpoador no $2^{\circ}$ semestre de 2010

Quadro 1 - Categorias da entrevista com os(as) professores(as) e seus aspectos relevantes

Quadro 2 - Formação educacional dos(as) professores(as) do Colégio Arpoador

Quadro 3 - Experiência profissional dos(as) professores(as) do Colégio Arpoador 


\section{Lista de gráficos}

Gráfico 1 - Porcentagem de alunos(as) aprovados(as), reprovados(as) e evadidos(as) nos três anos do ensino médio no Colégio Arpoador no primeiro semestre de 2010

Gráfico 2 - Porcentagem de alunos(as) aprovados(as), reprovados(as) e evadidos(as) nos três anos do ensino médio no Colégio Arpoador no segundo semestre de 2010

Gráfico 3 - Porcentagem de homens e mulheres no Colégio Arpoador no segundo semestre de 2010

Gráfico 4 - Cor/Raça declarada dos(as) alunos(as) do Colégio Arpoador no segundo semestre de 2010

Gráfico 5 - Orientação Sexual dos(as) alunos(as) do Colégio Arpoador no segundo semestre de 2010

Gráfico 6 - Religião dos(as) alunos(as) do Colégio Arpoador no segundo semestre de 2010

Gráfico 7 - Faixa de idade dos(as) alunos(as) do Colégio Arpoador no segundo semestre de 2010

Gráfico 8 - Estado civil dos(as) alunos(as) do Colégio Arpoador no segundo semestre de 2010

Gráfico 9 - Moradia dos(as) alunos(as) em relação à proximidade do Colégio Arpoador no segundo semestre de 2010

Gráfico 10 - Porcentagem de alunos(as) do Colégio Arpoador no segundo semestre de 2010 que moram em Comunidades

Gráfico 11 - Comunidades nas quais os(as) alunos(as) do Colégio Arpoador no segundo semestre de 2010 residem

Gráfico 12 - Porcentagem de alunos(as) do Colégio Arpoador no segundo semestre de 2010 que possuem casa própria, alugada, em pagamento ou cedida pelo empregador

Gráfico 13 - Região de origem dos(as) alunos(as) do Colégio Arpoador no segundo semestre de 2010

Gráfico 14 - Emprego e faixa salarial dos(as) alunos(as) do Colégio Arpoador no segundo semestre de 2010 
"Daí, mais uma vez, a necessidade da invenção da unidade na diversidade. Por isso é que o fato mesmo da busca da unidade na diferença, a luta por ela, como processo, significa já o começo da criação da multiculturalidade. É preciso reenfatizar que a multiculturalidade como fenômeno que implica a convivência num mesmo espaço de diferentes culturas não é algo natural e espontâneo. É uma criação histórica que implica decisão, vontade política mobilização, organização de cada grupo cultural com vistas a fins comuns. Que demanda, portanto, uma certa prática educativa coerente com esses objetivos. Que demanda uma nova ética fundada no respeito às diferenças." 